\title{
Detection of Multiresistance Tuberculosis in the Surrounding of Tuberculosis Patients with Multiresistant Bacillus in Kinshasa (DRC)
}

\author{
Kabedi B.M.J. ${ }^{1}$, Taba K. ${ }^{4}$, Kayembe N.J.M. ${ }^{2}$, Kayembe K.P. ${ }^{3}$, Lunguya M.O. ${ }^{1}$, Bisuta F.S. ${ }^{2}$, \\ Mbaya K.P. ${ }^{1}$, Muyembe T.J.J. ${ }^{1}$ \\ ${ }^{1}$ Department of Microbiology /Faculty of Medicine, University of Kinshasa \\ ${ }^{2}$ Department of Medicine Internal/ Faculty of Medicine, University of Kinshasa \\ ${ }^{3}$ School of Public Health/ Faculty of Medicine, University of Kinshasa \\ ${ }^{4}$ Department of Chemistry Organic/Faculty of Sciences/ University of Kinshasa

\section{* Address of Correspondence:}

\section{Doctor Marie José Kabedi Bajani} \\ Department of Microbiology/University clinics of Kinshasa, Faculty of Medicine/University of Kinshasa, \\ Democratic Republic of the Congo (DRC) \\ B.P: 1047 , KIN I/ DRC \\ E-mail: bedye2001 @yahoo.fr
}

\begin{abstract}

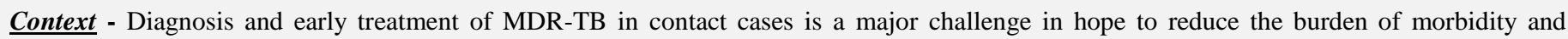
mortality due to this condition. Objectives - The objective was to assess the prevalence of drug-resistant TB and to compare the phenotypic and genotypic profile of the contact case with that of the index. Material and Methods - Prospective cohort study of 240 household contacts of 59 MDR-TB cases diagnosed and having a positive Ziehl at Elonga, St Alphonse and CUK CSDT was carried out from July 1, 2011 to August 28, 2013. Two sputum specimens were examined in each suspected tuberculosis contact for Ziehl-Neelsen's Koch bacillus and cultured for susceptibility testing on Lowensten-Jensen medium. The tuberculin test was performed on each contact and the spoligotyping of the index of contact cases was performed to determine whether the strains were epidemiologically linked. Results - Twenty-nine contacts out of 240 (12.1\%) had symptoms suggestive of tuberculosis and 29 strains of Mycobacterium were isolated from 18 HIV-positive and 11 HIV-negative patients. The identification of these strains shows 26 Mycobacterium. tuberculosis and 6 Mycobacterium africanum. Of these contacts, 23 had a positive Ziehl and 6 had a negative IDR and Ziehl with positive HIV status. The antibiogram performed shows 16 resistant strains at least to one antituberculosis drug. MDR-TB (6.3\%) and among them $4.2 \%$ preXDR (10) and $0.4 \%$ XDR-TB were detected. The phenotypic profile of 15 strains of the contacts corresponded to that of the index case and among the 8 typed strains, six were identical to the source case and 2 had a different profile. Conclusion - The survey determined the prevalence of TB and MDR-TB among the index case contacts. The high proportion reported in this survey is reminiscent of the WHO's alarm bell for early detection to halt the spread of the disease in the population.
\end{abstract}

Keywords: Detection; contact; multidrug-resistant tuberculosis; Kinshasa.

\section{Introduction}

The spread of multidrug-resistant (MDR-TB) strains of tuberculosis has become a challenge and represents a serious threat to the success of TB control. HIV co-infection complicates more this situation. ${ }^{[1]}$

In 2016, the World Health Organization (WHO) estimated that 10.4 million people became sick of tuberculosis worldwide, including 600000 new cases resistance to rifampicin (RR-TB), and 490000 MDR-TB case. ${ }^{[1]}$ The proportion of $4.1 \%$ of MDR-TB is found in new cases and $19 \%$ among retirees. ${ }^{[1]}$ The co-infection rate is estimated at $11 \%$ worldwide, of which $74 \%$ in Africa. ${ }^{[1]}$
The Democratic Republic of Congo (DRC) is among the 30 countries where $85 \%$ of the global burden of MDR-TB is found, with a $9.7 \%$ incidence of RR-TB / MDR-TB ${ }^{[1]}$ According to the same report of 2017, 3,600 cases of TB-Drug-Resistant (RR-TB and MDR-TB) were estimated, of which $2.2 \%$ in new cases and $17 \%$ among retirees. ${ }^{[1]}$

This worrisome situation of tuberculosis and its complicated forms has enabled the World Health Assembly to adopt the End TB strategy to end the global tuberculosis epidemic by reducing the number of deaths by $95 \%$ and the incidence of tuberculosis by $90 \%$ between 2015-2035 as the future of TB control depends in part on the success or failure of MDR-TB extension control. ${ }^{[1,2,3,4,5]}$ This 


\section{International Journal of Innovative Research in Medical Science (IJIRMS) \\ Volume 03 Issue 11 Nov 2018, ISSN: 2455-8737, Imp. Factor - 4.102 \\ Available online at $-\underline{w w w . i j i r m s . i n}$}

strategy provides the baseline for effective tools to prevent the onset or spread of MDR-TB by early and rapid detection of PRTB. ${ }^{[1,2,3,4,5]}$

The problem of screening, however, arises in people close to patients with contagious tuberculosis who are most at risk of tuberculosis infection..$^{[1,2,3,4,5,6]}$ and who unfortunately are not detected in time to prevent the spread of the strain in the community as this screening is passively and not actively.

Thus, the discovery of a case of tuberculosis implies the possibility of fast detection to avoid putting a resistant patient under inappropriate treatment, and to increase cure rate to avoid failures and relapses. ${ }^{[2,3,4,5]}$ This research is a priority to quickly identify and prevent secondary cases. . $^{[2,3,4,5]}$

It is within this framework that we initiated this survey which had as a main objective to assess the prevalence of multidrug-resistant tuberculosis (MDR-TB) contacts; the second objective was to determine the phenotypic and genotypic profile of strains isolated from contact MDR-TB cases and compare them to that of the index.

\section{Subjects and Methods}

Type, site and study population: Prospective including 240 household contacts of 59 MDR-TB cases diagnosed and having a positive Ziehl. The survey took place in the different centers of screening and treatment (CSDT) of tuberculosis (Elonga, St Alphonse and CUK) of the city of Kinshasa province between July 1, 2011 and February 28, 2015.

\section{Data collection methods}

On the basis of the lists drawn from the tuberculosis register, the invitations were sent to the families of the tuberculosis patients concerned. Two sputum samples were collected from household contacts with symptoms suggestive of tuberculosis (weight loss, anorexia, asthenia, productive cough \pm 2 weeks, fever, sweating, and chest pain) for the detection of acid-fast alkali bacilli by the Ziehl technique at CSDT first and then sputums were sent to the Mycobacteria Laboratory of the Faculty of Medicine, University of Kinshasa for stump isolation and antibiogram on LJ using the proportion technique of Canetti and al. ${ }^{[6]}$

Sputum was processed by the Petroff method using $4 \%$ sodium hydroxide and the inoculum of the Ziehl positive samples were seeded directly onto two tubes containing Lowenstein - Jensen (LJ) pure medium and other tubes containing LJ incorporated antituberculous molecules at different concentrations namely Isoniazid $(0.2 \mu \mathrm{g} / \mathrm{ml})$; Rifampicin $(40 \mu \mathrm{g} / \mathrm{ml})$; Ethambutol $(2 \mu \mathrm{g} /$ $\mathrm{ml})$; Streptomycin $(4 \mu \mathrm{g} / \mathrm{ml})$; Ofloxacin $(4 \mu \mathrm{g} / \mathrm{ml})$ and Kanamycin $(30 \mu \mathrm{g} / \mathrm{ml})$ for the direct method. ${ }^{[6]}$ On the other hand, the Ziehl negative samples were inoculated only on the LJ medium and after growth of the seeds, the biochemical identification was carried out by the Niacin test and the 2 thiophene carboxylic acid $(2 \mu \mathrm{g} / \mathrm{ml})$. Antibiogram by the indirect method of proportion was performed after isolation. ${ }^{[6]}$ Furthermore, HIV serology was performed at the CDST according to the protocol of the National AIDS Control Program (PNLS) using rapid tests (to determines and double check) which are in vitro immuno-chromatographic tests with visual reading for qualitative detection of anti-HIV-1 and
anti-HIV-2 antibodies in serum. ${ }^{[5,6,7]}$ A tuberculin test was carried out in all the persons selected in this study in order to estimate the prevalence of tuberculin reactivity. ${ }^{[5,6]}$ The data was collected using a structured questionnaire with face-to-face interview. Strains of Mycobacterium were typed by spoligotyping at IMT Antwerp.

\section{Ethical consideration}

The study received the approval of the Ethics Committee of the School of Public Health of University of Kinshasa ( ${ }^{\circ}$ ESP / CE / 081/2010). The oral consent of the contacts or their guardian was obtained.

\section{Data processing}

The data was processed using the SPSS software version 23. The difference in the distribution frequency was achieved by the chisquare test. The significance of the results was assessed at the 5\% probability level and the $95 \%$ confidence interval (CI).

\section{Results}

Out of 310 invitations issued, 240(77\%) responded, of which 111 (46.2\%) were women and $129(53.8 \%)$ were men, with an average age of $33.5 \pm 13.55$ years, and the extremes ranged from 4 to 75 years old. The distribution of contacts by age group and sex is shown in Table 1:

Table I: Distribution of contacts by age group and sex

\begin{tabular}{|l|c|c|c|c|c|c|}
\hline Age group & \multicolumn{2}{|c|}{ Men } & \multicolumn{2}{c|}{ Women } & \multicolumn{2}{c|}{ Total } \\
\hline & n & \% & n & \% & N & \% \\
\hline $0-9$ & 4 & 1.7 & 3 & 1.2 & 7 & 2.9 \\
$10-19$ & 18 & 7.5 & 11 & 4.6 & 29 & 12.1 \\
$20-54$ & 95 & 39.6 & 89 & 37.1 & 184 & 76.7 \\
55 and over & 12 & 5.0 & 8 & 3.3 & 20 & 8.3 \\
\hline Total & 129 & 53.8 & 111 & 46.2 & 240 & 100 \\
\hline
\end{tabular}

The age group of 20-54 was the most concerned (76.7\%) followed by those of $10-19(12.1 \%)$ and 55 and over (8.3\%). The distribution of contacts according to the positivity of the tests carried out is illustrated in Table 2:

Table II: Distribution of contacts according to test positivity

\begin{tabular}{|l|c|c|c|c|c|c|}
\hline Tests & \multicolumn{2}{|c|}{ Positive } & \multicolumn{2}{c|}{ Negative } & \multicolumn{2}{c|}{ Total } \\
\hline & n & \% & n & \% & n & \% \\
\hline IDR & 38 & 15.8 & 202 & 84.2 & 240 & 100 \\
ZN & 23 & 9.6 & 217 & 90.4 & 240 & 100 \\
LJ & 29 & 12.1 & 211 & 87.9 & 240 & 100 \\
Serology HIV & 29 & 12.1 & 211 & 87.9 & 240 & 100 \\
\hline
\end{tabular}

As seen in table 2, $15.8 \%$ of contacts were positive for IDR (identifiable Guerin and Calmette bacillary scarring between 12$13 \mathrm{~mm}$ ) and among them, 9.6\% were positive (23) in Ziehl and $12.1 \%$ were positive (29) in LJ culture. In contrast, $12.1 \%$ had a positive HIV serology (29).Furthermore, 29 strains of Mycobacterium were isolated (12.1) including 6 africanum. Of these 18 strains were isolated from HIV-positive and 11 from HIVnegative. Six HIV positive patients were TPM0. The antibiogram showed that 16 strains of Mycobacterium tuberculosis (55.2\%) were resistant to at least one anti-tuberculosis drug and $44.8 \%$ (13) were sensitive to all anti-tuberculosis drugs. Fifteen (15) strains 


\section{International Journal of Innovative Research in Medical Science (IJIRMS) Volume 03 Issue 11 Nov 2018, ISSN: 2455-8737, Imp. Factor - 4.102 Available online at $-\underline{w w w . i j i r m s . i n}$}

(6.3\%) were MR-TB and among them, $4.2 \%$ preXDR (10) and $0.4 \%$ XDR-TB (1).

The phenotypic profile of 15 strains of the contact cases corresponded to that of the strains of the index case. Of the 8 strains of Mycobacterium typed, 6 had a genotype profile identical to that of the index case and 2 had a different profile.

\section{Discussion}

An effective and long-term way to reduce MDR-TB in a population is to rapidly diagnose cases and treat them appropriately in order to interrupt the chain of transmission. ${ }^{[1,2,3,4]}$

The purpose of this study was to determine the prevalence of TB and MDR-TB. Twenty three (9.6\%) patients were Ziehl positive and 29 strains $(12.1 \%)$ of Mycobacterium were isolated on LJ including 18 in HIV positive patients. The antibiogram showed that 16 strains of Mycobacterium tuberculosis (55.2\%) were resistant to at least one antituberculosis drug and $44.8 \%$ (13) were susceptible to all.

Fifteen (15) strains (6.3\%) were MR-TB and among them 4.2\% preXDR $(n=10)$ and $0.4 \%$ XDR-TB $(n=1)$. The phenotypic profile of the 15 strains of the contact cases corresponded to that of the strains of the index case. Of the 8 strains of Mycobacterium typed, 6 had a genotype profile identical to that of the index case and 2 had a different profile.

The discrete predominance of the male sex $(53.8 \%)$ in this survey, although not statistically significant $(\mathrm{p}=2.55)$, corroborate some authors who think that the difference could be due to the insufficiency of declaration of cases among women in developing countries. They also showed that men would be easier to screen than women because of certain socio-cultural barriers. ${ }^{[8,9]}$

The high proportion of patients co-infected with HIV (76.7\%) in the age group of 20 to 54 years corroborate many WHO reports that show that TB mainly affects the most mobile and the most economically active group..$^{[1,2,3,4]}$ This shows that the risk of coinfection increases with age. ${ }^{[1,2,3,4]}$

The rate of $15.8 \%$ of contacts (38) with an identifiable scar (12$13 \mathrm{~mm}$ ) reported in this survey is lower than those of 35, 38 and $29.7 \%$ respectively obtained by Lienhardt and al., ${ }^{[10]}$ Lee and al. ${ }^{[11]}$ and Elias and al. ${ }^{[12]}$ The diversity of rates could be explained by the degree of immunodepression of the patients not known and also by the size of samples.

The proportion of $9.6 \%$ smear-positive tuberculosis patients $(\mathrm{n}=$ 23) found in this study shows that people in contact with smearpositive TB patients are at greater risk of being infected with Mycobacterium. This frequency of Tuberculosis contacts (9.6\%) in our survey provide ample evidence that the disease is spreading in the Congolese community. ${ }^{[2,3]}$

The proportion of $9,6 \%$ found is however far superior to those of $1 \%, 2 \%$ and $3.45 \%$ described respectively by Aissa and al. ${ }^{[13]}$; Jones and al. ${ }^{[14]}$ and Gupta and al. ${ }^{[15]}$ in family contacts. It is also greater than the $3.3 \%$ reported by Grandjean and al. ${ }^{[16]}$ in family contacts of MDR-TB suspects and $4.8 \%$ in family contacts of tuberculosis patients sensitive to anti-TB molecules.
Unlike the Iwamoto and al. ${ }^{[17]}$ who reported a high number of 64 of tuberculosis cases in contact with an inpatient source case and Catho and al. ${ }^{[18]}$ who showed that out of 46 identified contacts of 20 adult MDR-TB cases, 5 children (11\%) presented secondary tuberculosis.

The tuberculosis prevalence rate of nearly $12.1 \%$ in our study is particularly attributable to the state of immunosuppression of most of our patients $(n=18)$. This rate is however similar to that reported by Eldholm and al. ${ }^{[19]}$ in a study on the impact of HIV coinfection on the development and transmission of MDR-TB. They have shown that HIV is an enhancer of TB outbreaks. ${ }^{[19]}$

The survey shows that the 6 patients with negative bacilloscopy had a positive HIV serology. ${ }^{[20,21,22]}$ Particular attention should be given to smear-negative tuberculosis (6 out of 29 strains isolated) although less contagious, several studies have shown the contamination of the surrounding and the nursing staff by this category of patients. ${ }^{[22,23]}$ These cases are most common in immunocompromised patients with CD4 200. ${ }^{[22,23]}$

But since the degree of immunosuppression was not determined due to lack of lymphocyte typing and viral load, it is impossible for us to clarify this issue. Thus, targeted prevention measures may be useful in reducing transmission and decreasing the progression of latent tuberculosis to TB disease. HIV-related immunodeficiency is known to promote the transition from latent tuberculosis to active tuberculosis, and late detection of co-infection is the leading cause of death in co-infected patients. . $^{[1,3,19,22,23]}$

The proportion of $6.3 \%$ MDR-TB $(\mathrm{n}=15), 4.2 \%$ preXDR $(\mathrm{n}=10)$, and $0.4 \%$ XDR-TB $(n=1)$ reported in this survey is a significant problem for Public Health, through the spread of drug-resistant strains among the Congolese population and also an obstacle to the fight against tuberculosis in the country. Admittedly, people close to patients with contagious tuberculosis, are most at risk of TB infection, however not all people in contact with a patient with contagious tuberculosis have the same susceptibility to infection and disease. ${ }^{[10,11,12,13,14,15,16,17,18,19,20,21,22,23]}$ Some of them will be infected. ${ }^{[10,11,12,13,14,15,16,17,18,19,20,21,22,23]}$ This result, however, is less than $11 \%$ reported by Catho and al. in a survey of 46 identified contacts of 20 adult MDR-TB cases. ${ }^{[18]}$

The survey also reports that 15 strains had the same phenotype with those of the index case. This result indicates that these contacts could be infected by the strain of the index case. But, due to the lack of discriminating character of the phenotypic test, the molecular typing (genotyping) of the isolated strains was carried out to determine the origin of the isolated strains in the contacts. Spoligotyping is of paramount importance to effectively guide epidemiological investigations, to define the transmission and facilitate epidemiological surveillance of the disease. ${ }^{[24,25,26]}$

After typing 8 strains, we found that 6 had the same profile as the source case, which means that the contacts were contaminated by the strains of the source case and while 2 strains had a different profile of the source case, which shows that the two contacts were contaminated by strains other than those of the source case.

The 6 strains of M.africanum isolated show that the patients were infected with a strain from West Africa. ${ }^{[27]}$ 


\section{International Journal of Innovative Research in Medical Science (IJIRMS) Volume 03 Issue 11 Nov 2018, ISSN: 2455-8737, Imp. Factor - 4.102 \\ Available online at $-\underline{w w w . i j i r m s . i n}$}

The results of this study must take into account some limitations for their interpretation. First, the number of CSDTs (3) selected for the survey may have introduced a selection bias, and the small size of the sample, does not allow extrapolation of the results. Second, the lack of lymphocyte typing and viral load could not be used to determine the degree of immunosuppression of our co-infected patients. These limitations, however, do not remove the validity of this study, since it has shown the existence of the transmission of tuberculosis and its complicated form (MDR-TB) in the entourage of the tuberculosis patient. This could be a barrier to achieving WHO's "END-TB" targets to reduce the number of deaths to $95 \%$ and the impact to $90 \%$ by $2015-2035$. Finally, the lack of typing by MIRU VNTR is a more discriminating test than spoligotyping.

\section{Conclusion}

Screening of household contacts of MDR-TB index cases allows early detection of TB and its complicated form (MDR-TB). The high proportion of MDR-TB recalls WHO's alarm for early detection to stop disease progression in the population.

Conflict of interest: None Declared.

\section{Acknowledgements}

We acknowledge all the technicians of different CSDT for their support and collaboration. We also acknowledge Mourad GUMUSBOGA of IMT Antwerp for his support of molecular analyzes. We are also grateful for all those who give us a help during this study.

\section{References}

[1] World Health Organization. Global tuberculosis control: Who report 2017.

[2] Partnership, S.T. The global plan to stop TB, 2006-2015, actions for lite: towards a world free of tuberculosis. Int $\mathrm{J}$ Tuberc lung Dis, 2006. 10(3): p. 240-1.

[3] Enquêtes autour d'un cas de tuberculose Recommandations pratiques Groupe de travail du CSHPF - Mars 2006.

[4] World Health Organisation. Directives pour intensification du dépistage de la tuberculose et administration du traitement préventif l'isoniazide chez les personnes vivant avec le VIH dans un contexte de ressources limitées. OMS; Genève, 2011. http: //whqhbdoc. Who.int/ publication/ 2011/9789242500707.

[5] Programme national de lutte contre la Tuberculose. Programme antituberculeux intégré aux soins de santé de base, 4ème édition (PATI 4). PNT/ RDC, 2008.

[6] Canetti G., Froman F., Grosset J. et al. (1963). Mycobacteria: laboratory methods for testing drug sensitivity and resistance. Bulletin of the World Health Organization 29,565- 78.

[7] PNLS. Rapport épidémiologique de surveillance du VIH chez les femmes enceintes fréquentant les structures de CPN en 2009. Kinshasa. PN MLS, 2010. www.bdd.pn,ls.cd/search/all.php.

[8] Borgdorff MW, Nagelkerke NJD, Dye C, Nunn P. Genre et tuberculose: une comparaison entre les enquêtes de prévalence et les données de déclaration pour explorer les différences entre sexes dans la détection des cas. Int $\mathrm{J}$ Tuberc Lung Dis 2000; 4(2): 123-132.

[9] Crampin AC, Glynn JR, Floyd S, Malema SS, Mwinnuka VK, Ngwira BMM, Mzaungulu FD, Warndorff DK, Fine PEM. Tuberculose en fonction du sexe: exploration des types de la maladie dans une étude cas-contrôle au Malawi. Int J Tuberc Lung Dis, 2004, 8(2): 194-203.

[10] Lienhart C, Sillah J, Fielding K, Doukors S, Manneh K, Zarndoff D, Bennett S, Mc Adan K. Risk factors for tuberculosis infection in children in contact with infectious tuberculosis cases in the Gambia, West Africa. Pediatrics 2003, 111 (5): e608-14.

[11] Lee SJ, Lee SH, Kim YE, Cho YR, Hwang YS, Kim HJ, Menzies D. Risk factors for latent tuberculosis infection in close contacts of active tuberculosis patients in South Korea: a prospective cohort study. BMC Infect Dis. 2014; 18; 14: 566. Doi: 10.1186/S12879-014- 0566-4.

[12] Elias D, Akuffo N, Abate E, Mekonnen Y, Aseffa A, Britton S. Risk of tuberculosis infection in adolescents and adults in a rural community in Ethiopa. Int $\mathrm{J}$ Tuberc Lung Dis. 2016; 20(2): 218-22. Doi: 10.5588/itld.15.0675.

[13] Aissa K, Madhi F, Ronsin N, et al. Evaluation of model for efficient screening of tuberculosis contact subjects. Am J RespirCrit care Med 2008 may 1; 177 (9): 1041-71

[14] Jones-López EC1, Acuña-Villaorduña C2, Ssebidandi M3, Gaeddert M2, Kubiak RW2, Ayakaka I3, Blanc LF4, Joloba M5, Okwera A6, Fennelly KP7. Toux Aérosols de MycobacteriumtuberculosisPredict Maladie Tuberculose Incident dans Contacts ménagers. Clin Infect Dis. 2016 Mar 29. pii: ciw199. [Epub ahead of print]

[15] Gupta H, Kant S, Jain A, Natu SM, Ahluwalia S. Initial drug resistance pattern among pulmonary tuberculosis patients. Lung J Tuberc. 2013 Jul; 60(3):154-61.

[16] Grandjean L, Gilman RH, Martin L, Soto E, Castro B, Lopew S, Coronel J, Castillo E, Alarcon V, lopez V, San Miguel A, Quispe N, Asencios L, Dye C, Moore DA. Transmission of Multidrug Resistant and Drug Susceptible tuberculosis within Households: A prospective Cohort Study. PLoS Med. 2015 Jun 23; 12(6): e1001843; discussion e1001843. Doi: 10.1371/ journal.pmed. 1001843. eCollection 2015 Jun.

[17] Iwamoto S, Yano S, Nishikawa E, Tada M, Kadowaki T, Kimura M, Kobayashi K, Ikeda T. An outbreak of pulmonary tuberculosis due to definite exogenous reinfection among elderly individuals in welfare facilities.Kekkaku 2016 April; 91(4): 451-5. Japane se. PubMed PMID: 27530017.

[18] Catho G, Senechal A, Ronnaux-Baron AS, Valour F, Perpoint T, Bouaziz A, Dumitriescu O, Reix P, Pedone C, Ader F, LyonTB Study Group. Children exposed to multidrug-resistant tuberculosis: How should we manage: Analysis of 46 child contacts and review of the literature. Rev PneumolClin. 2015 Dec; 71(6): 335-41. Doi: 10.1016/J.2015.05.003. Epub 2015 jul 17.

[19] Eldholm V, Rieux A, Monteserin J, Lopez JM, Palmero D, Lopez B, RitacCo-V, Didelot X,Balloux F. Impact of HIV Co-infection on the evolution and transmission of multidrug resistant tuberculosis. Elife. 2016 Aug 9; 5.pii: 
e16644. Doi: 10.7554/elife. 16644. Pubmed PMID: 27502557; Pub,ed Central PMCD: P?C4978521.

[20] Kabedi Bajani MJ, Kayembe Ntumba JM, Kashongwe Munogolo Z, Bisuta Fueza S,Mbaya Kalumba P, Taba Kalulu M, Muyembe Tamfum JJ. GEN-XPERT® MTB/RIF Contribution in the Diagnosis of Pulmonary Tuberculosis with a Negative Bacilloscopy in Kinshasa (DRC). Int J Med Res Prof.2017; 3(4); 160-63.

[21] Kabedi Bajani MJ, Kayembe Ntumba JM, Kashongwe Munogolo Z, Bisuta Fueza S, Mbaya Kalumba P, Taba Kalulu M, Muyembe Tamfum JJ. Comparison of Classical Conventional Tests to XPERT MTB / RIF in the Diagnosis of Tuberculosis in People Living With HIV in Kinshasa. Int J Med Res Prof.2017; 3(4); 88-92.

[22] Theron G, Peter J, van Zyl-Smit R, et al. Evaluation of the Xpert MTB/RIF assay for the diagnosis of pulmonary tuberculosis in a high HIV prevalence setting. Am J Respir CritCareMed2011; 184:132-140.

[23] Hernandez-Garduno E, Cook V, Kunimoto D, Elwood RK, Black WA, FitzGerald JM.Transmission of tuberculosis from smear negative patients: a molecular epidemiology study. Thorax 2004; 59: 286-90.

[24] Jagielski T1, Augustynowicz-Kopec E, Zozio T, Rastogi $\mathrm{N}$, Zwolska Z. Spoligotype-based comparative population structure analysis of multidrug-resistant and isoniazid-monoresistant Mycobacterium tuberculosis complex clinical isolates in Poland. J Clin Microbiol. 2010; Nov;48(11):3899-909. doi: 10.1128/JCM.0057210. Epub 2010 Sep 1.

[25] Augustynowicz-Kopeć E1, Jagielski T, Kozińska M, Zabost A, Zwolska Z. The significance of spoligotyping method in epidemiological investigations of tuberculosis Pneumonol Alergol Pol. 2007;75(1):22-31.

[26] Merker M1,2, Kohl TA1,2, Niemann S3,4, Supply P5. The Evolution of Strain Typing in the Mycobacterium tuberculosis Complex. Adv Exp Med Biol. 2017; 1019:43-78. doi: 10.1007/978-3-319-64371-7_3.
[27] De Jong BC, Antonio M, Gagneux S. Mycobacterium africanum--review of an important cause of human tuberculosis in West Africa. PLoS Negl Trop Dis. 2010; Sep 28;4(9):e744. Review.

\section{Author Details:}

1. Doctor KABEDI BAJANI MARIE JOSE: Spécialist DEPARTMENT OF MICROBIOLOGY/Author Correspondence; E-mail: bedye2001 @yahoo.fr

2. Professor MUYEMBE TAMFUM JEAN JACQUES: DEPARTMENT OF MICROBIOLOGY/FACULTY OF MEDICINE/UNIVERSITY OF KINSHASA; Coauthor; muyembet@gmail.fr

3. Professor LUNGUYA METILA OCTAVIE: DEPARTMENT OF MICROBIOLOGY/ FACULTY OF MEDICINE/UNIVERSITY OF KINSHASA; Coauthor; Email: octmetila@ yahoo.fr

4. Biologist MBAYA KALUMBA PAULIN: DEPARTMENT OF MICROBIOLOGY/ FACULTY OF MEDICINE/UNIVERSITY OF KINSHASA; Coauthor; E-mail:pmbaya 2001@ yahoo.fr

5. Professor KAYEMBE NTUMBA JEAN MARIE: DEPARTMENT OF MEDICINE /FACULTY OF MEDICINE/UNIVERSITY OF KINSHASA; Coauthor; E-mail: drjmkayembe@ yahoo.com

6. Doctor BISUTA FUEZA SERGE: DEPARTMENT OF MEDICINE /FACULTY OF MEDICINE/UNIVERSITY OF KINSHASA; Co-author; Email: bisutafueza@ yahoo.fr

7. Professor KAYEMBE KALAMBAY PATRICK: SCHOOL OF PUBLIC HEALTH / FACULTY OF MEDICINE/UNIVERSITY OF KINSHASA; Coauthor; E-mail: patkayembe@ gmail.com

8. Professor TABA KALULU: Laboratory of chemistry organic, Department of chemistry, Faculty of sciences, University of Kinshasa, DRC. Co-author; Tabakalulu@ yahoo.fr 